\title{
SPECTROSCOPIC DATA
}



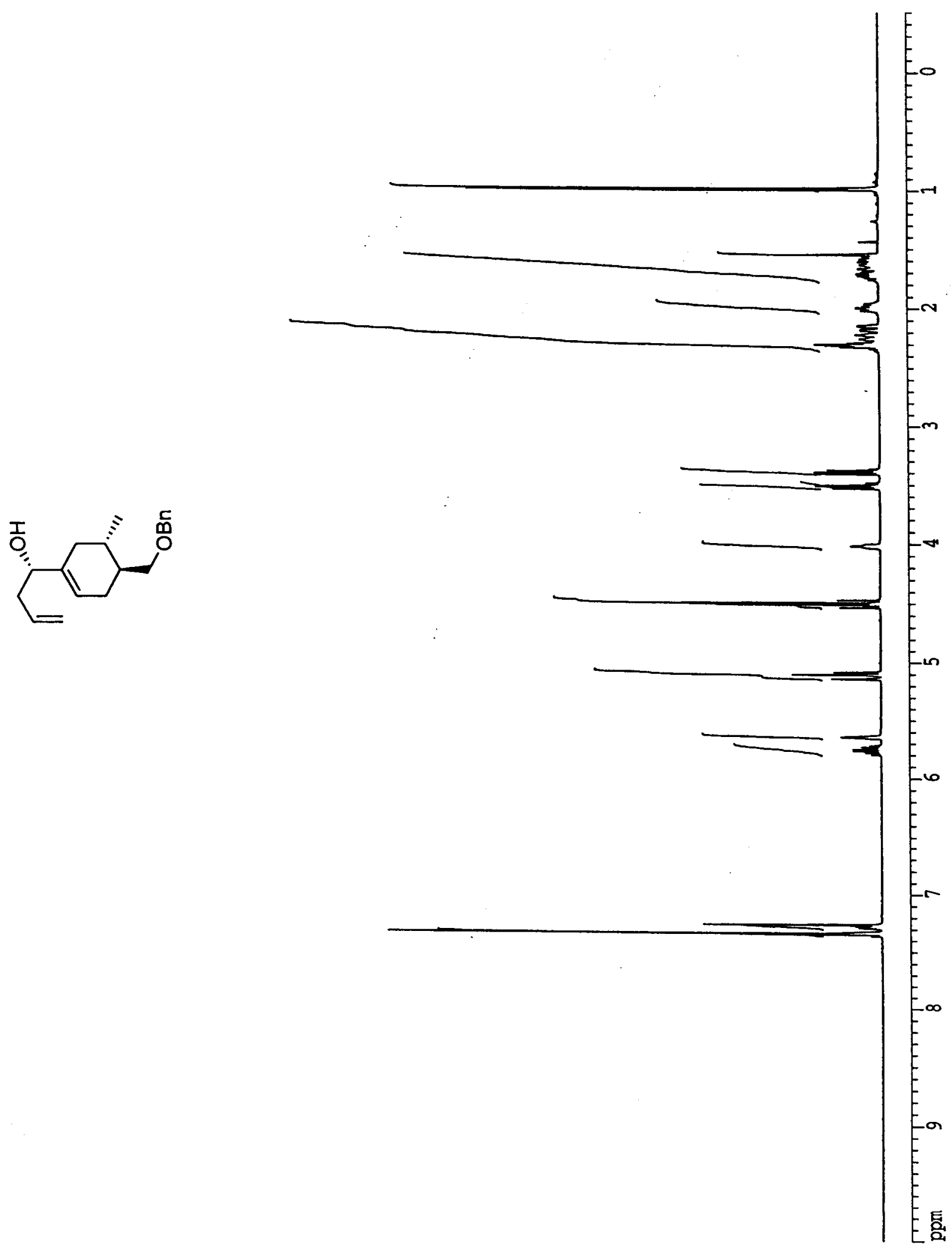

$500 \mathrm{MHz}{ }^{1} \mathrm{H}$ Spectrum of $(+)-17$ in $\mathrm{CDCl}_{3}$ 

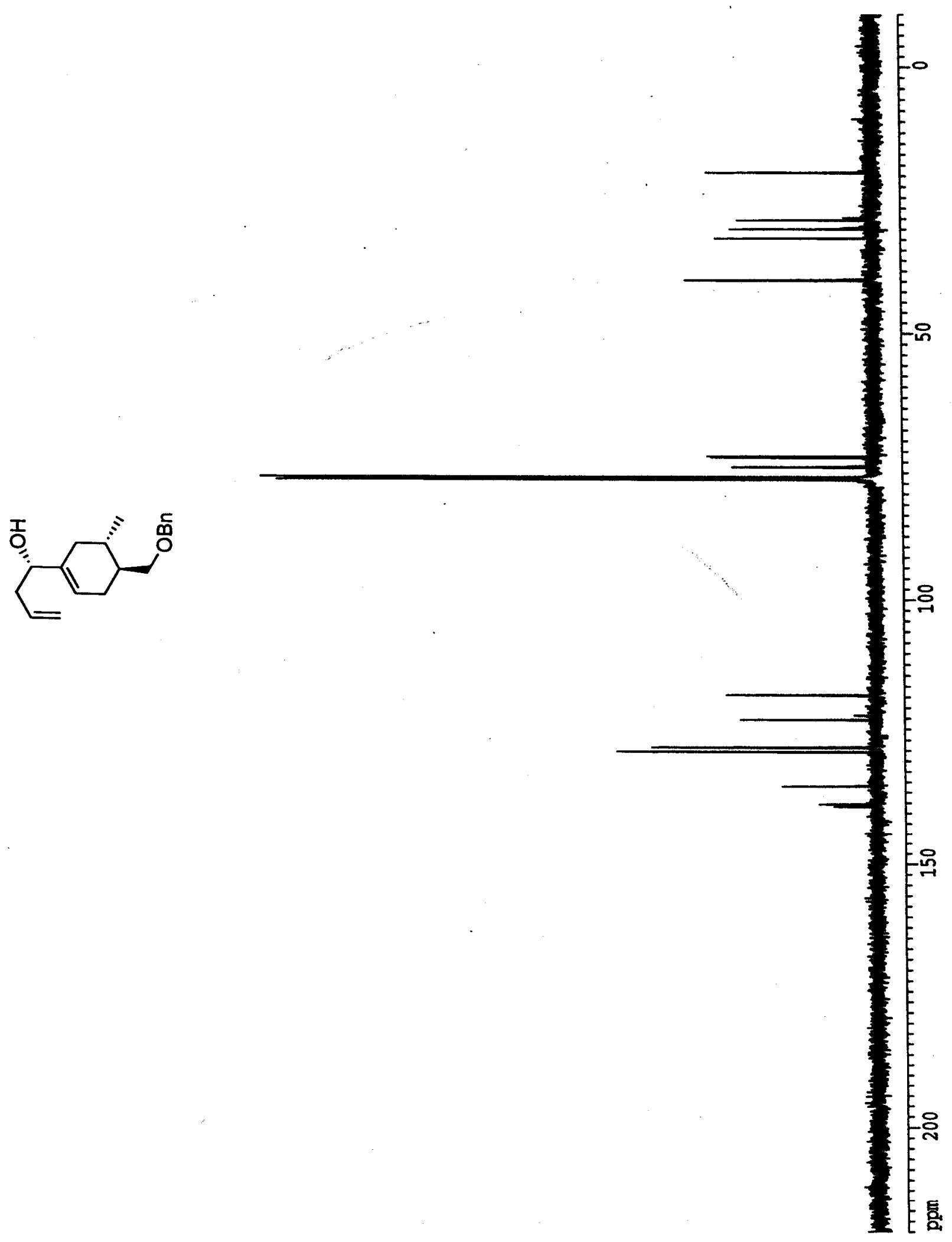

$125 \mathrm{MHz}{ }^{13} \mathrm{C}$ Spectrum of (+)-17 in $\mathrm{CDCl}_{3}$ 

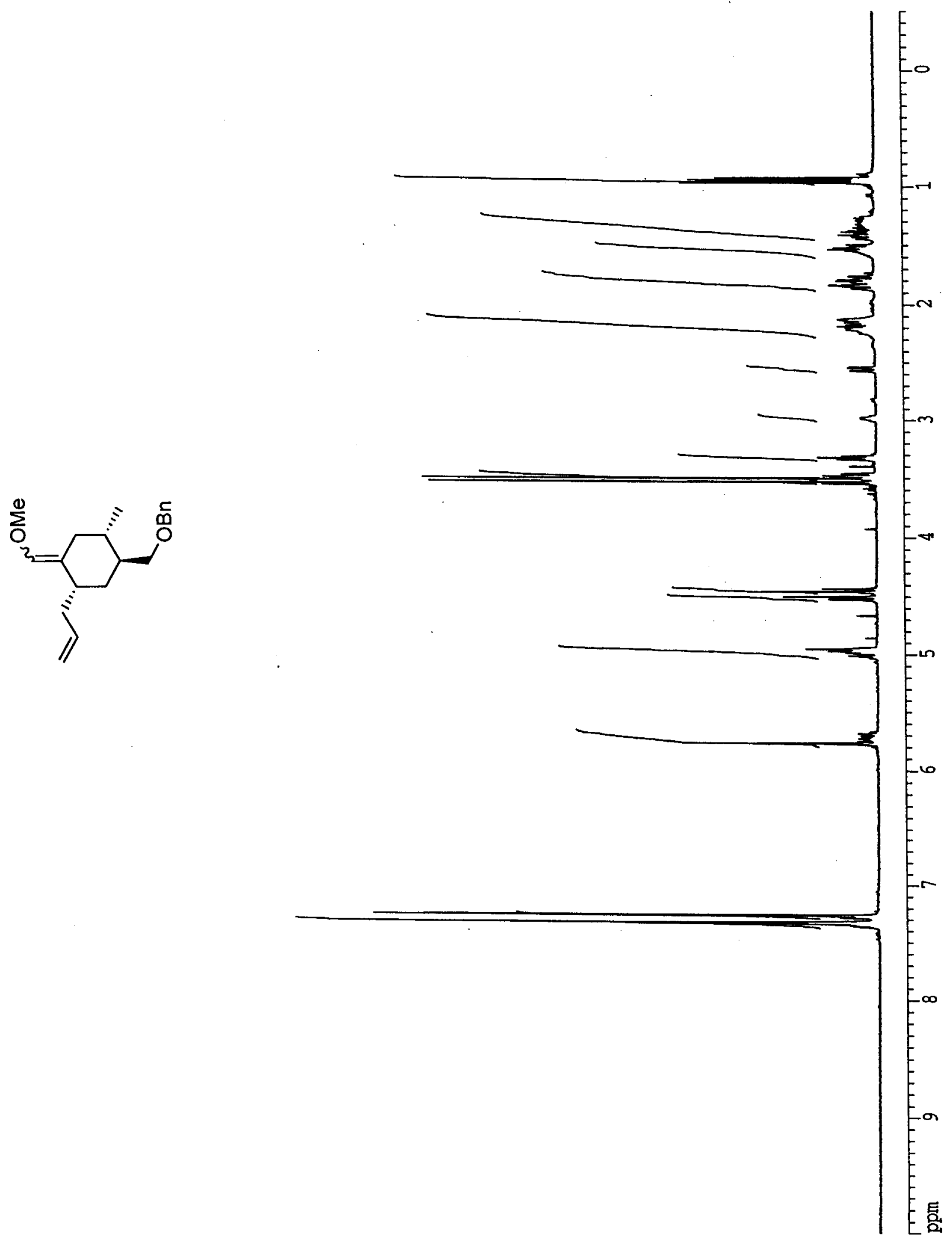

$500 \mathrm{MHz}{ }^{1} \mathrm{H}$ Spectrum of 18 in $\mathrm{CDCl}_{3}$ 

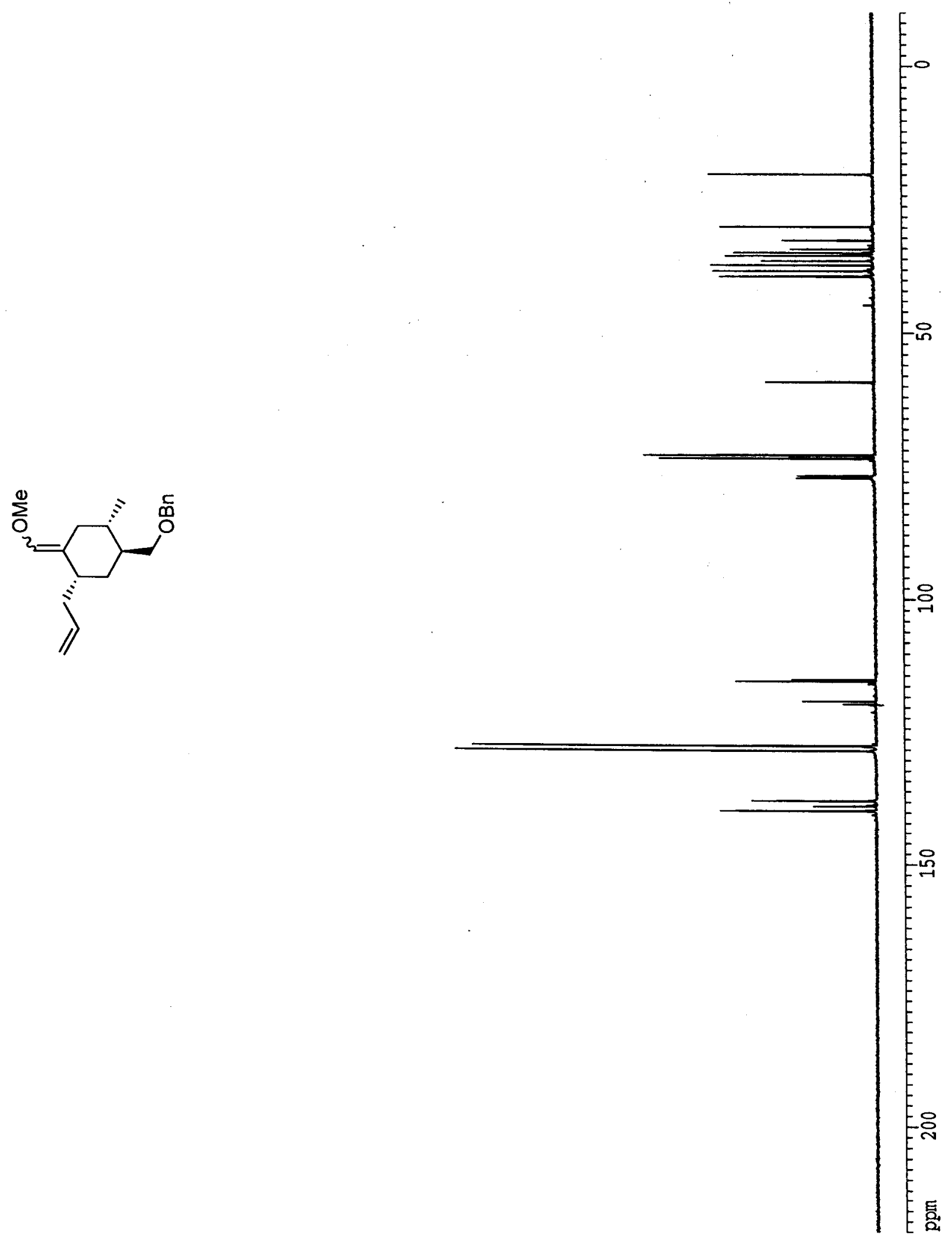

$125 \mathrm{MHz}{ }^{13} \mathrm{C}$ Spectrum of 18 in $\mathrm{CDCl}_{3}$ 


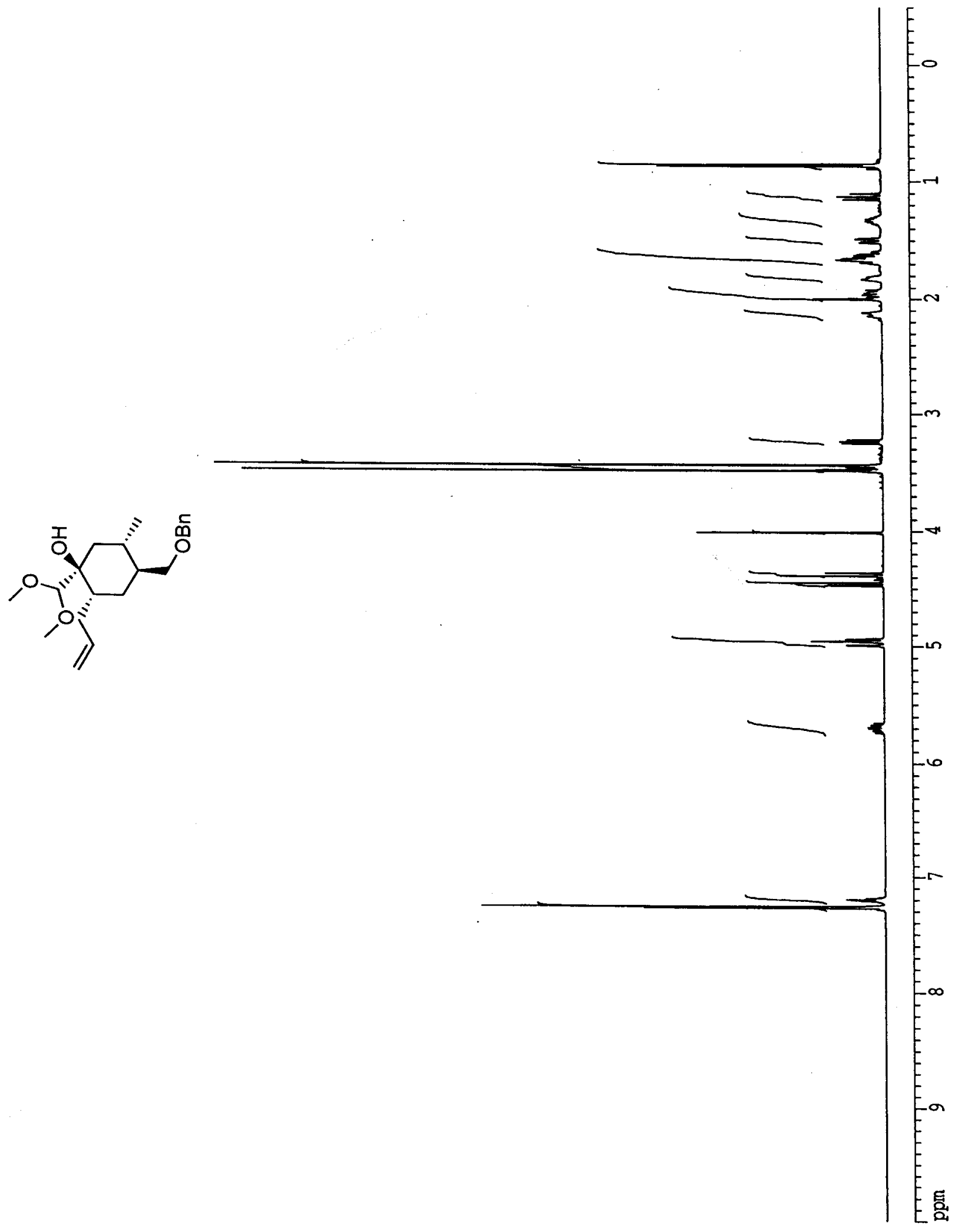

$500 \mathrm{MHz}{ }^{1} \mathrm{H}$ Spectrum of (+)-S1 in $\mathrm{CDCl}_{3}$ 

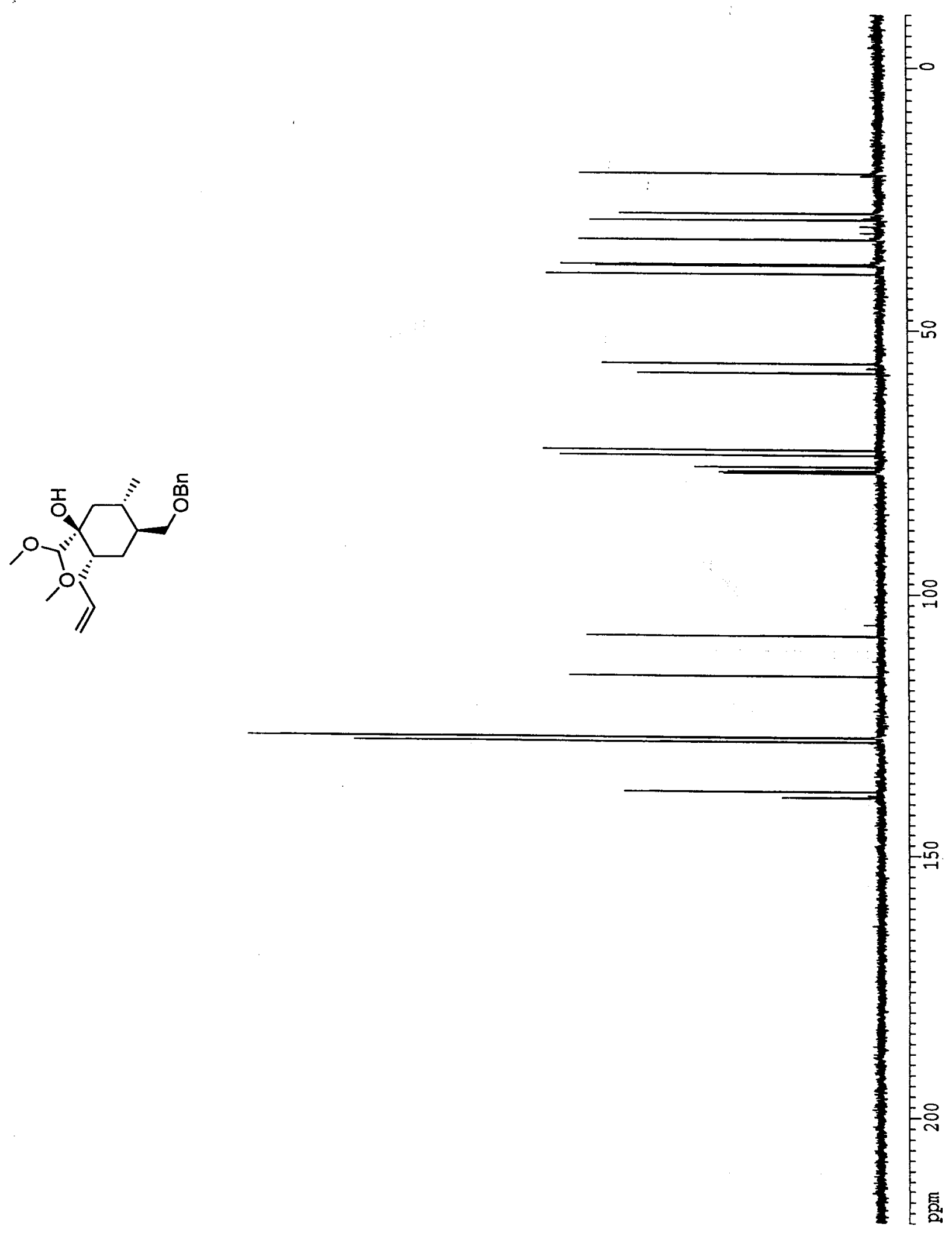

$125 \mathrm{MHz}{ }^{13} \mathrm{C}$ Spectrum of (+)-S1 in $\mathrm{CDCl}_{3}$ 


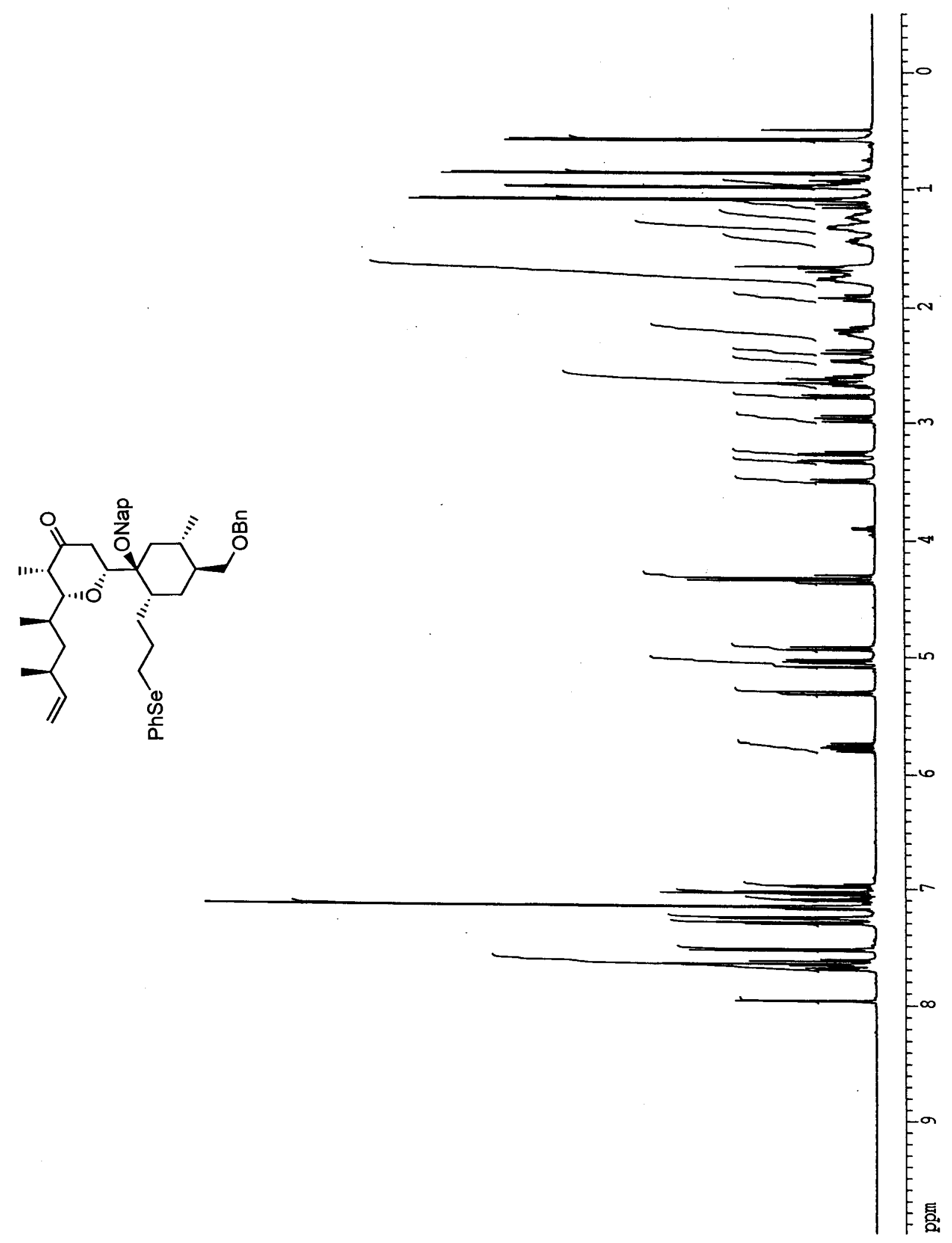

$500 \mathrm{MHz}{ }^{1} \mathrm{H}$ Spectrum of (+)-24 in $\mathrm{C}_{6} \mathrm{D}_{6}$ 


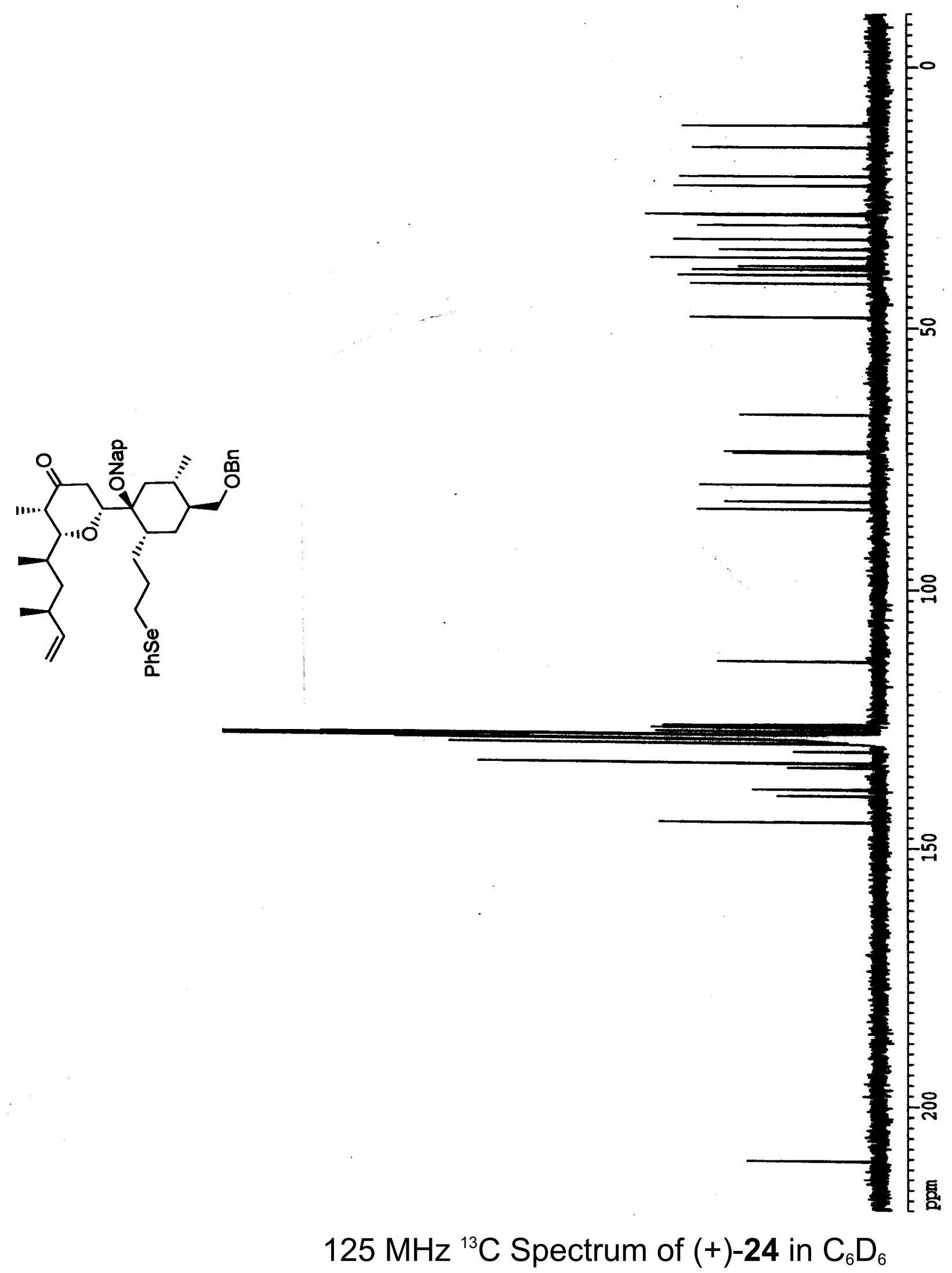




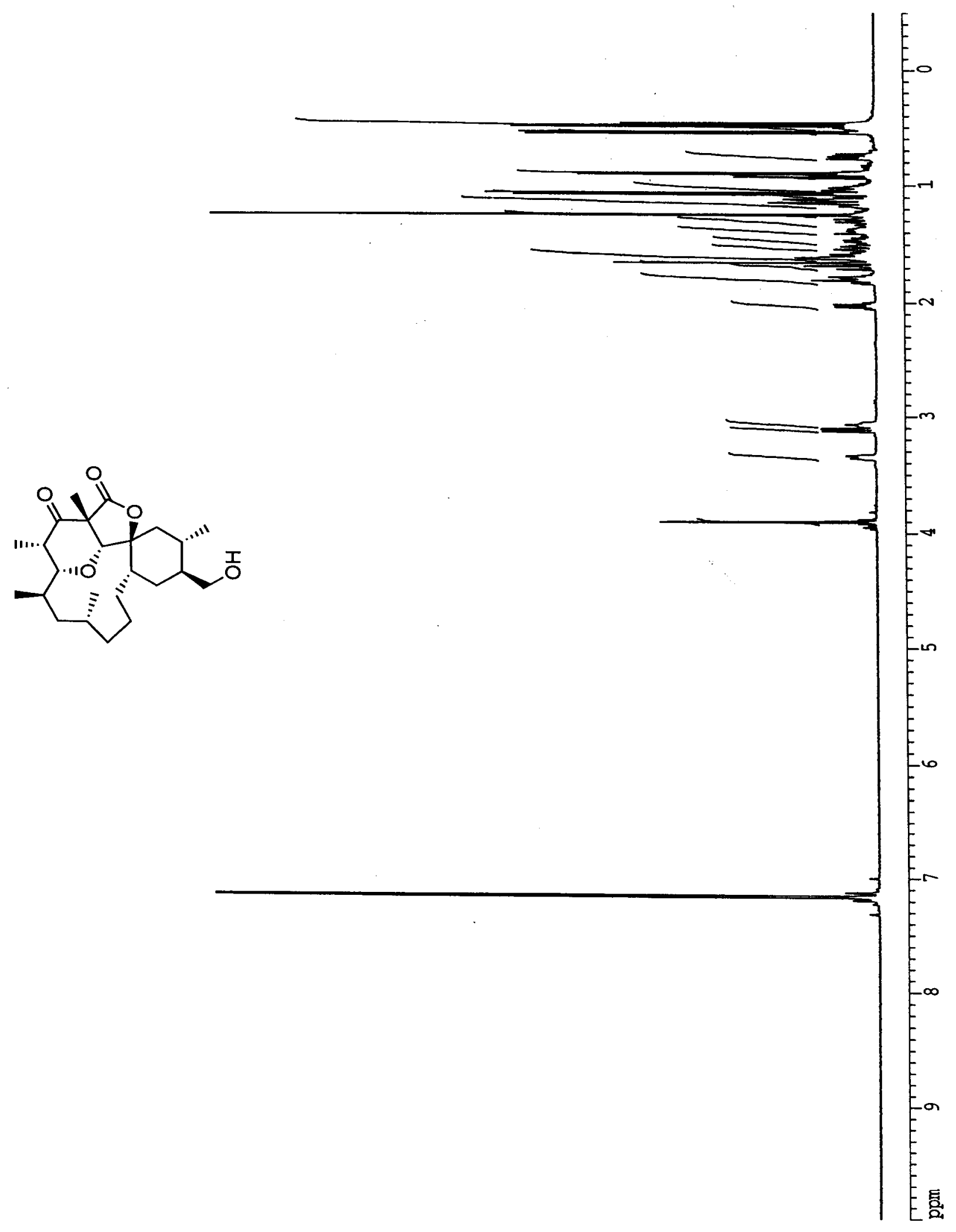

$500 \mathrm{MHz}{ }^{1} \mathrm{H}$ Spectrum of (-)-29 in $\mathrm{C}_{6} \mathrm{D}_{6}$ 

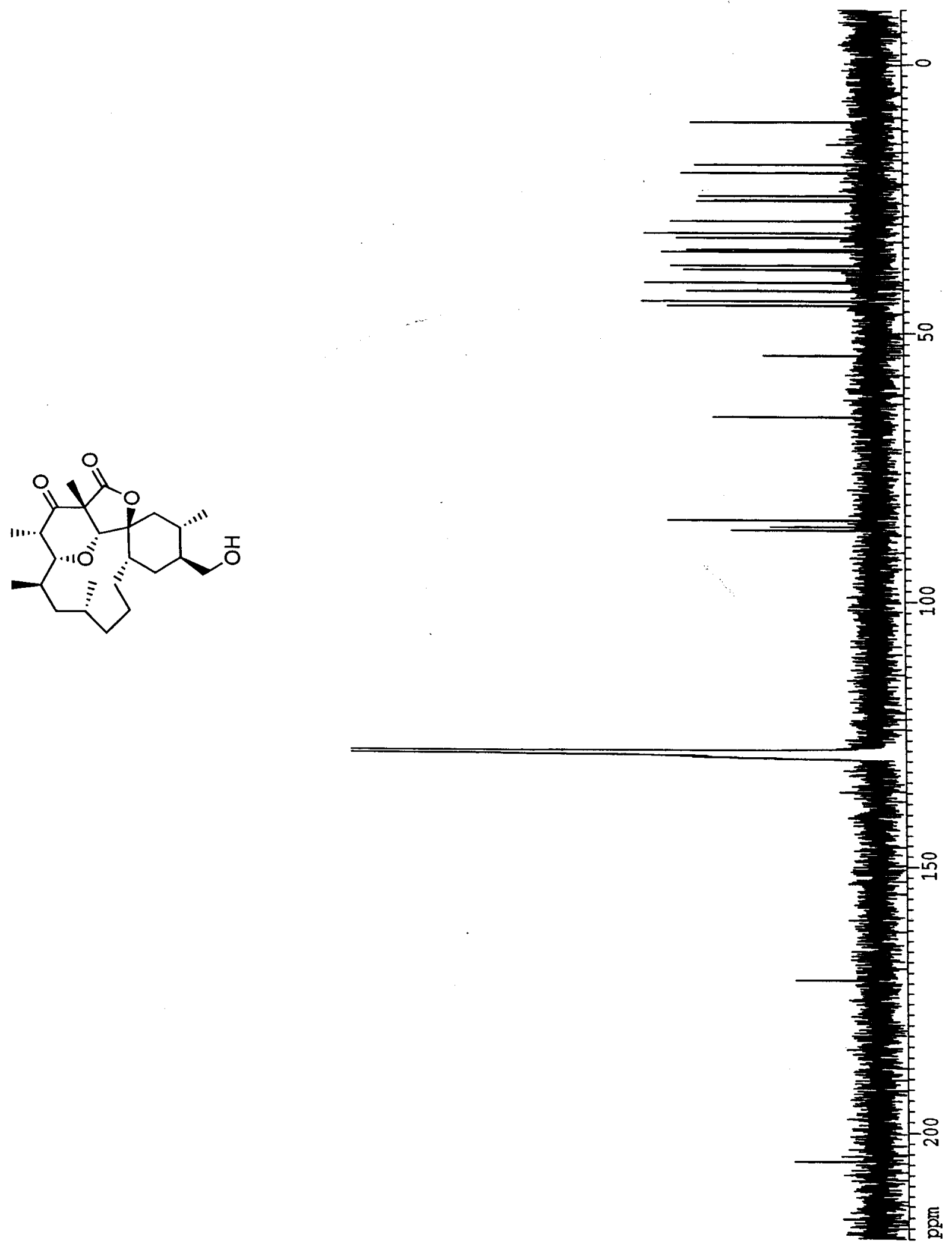

$125 \mathrm{MHz}{ }^{13} \mathrm{C}$ Spectrum of (-)-29 in $\mathrm{C}_{6} \mathrm{D}_{6}$ 

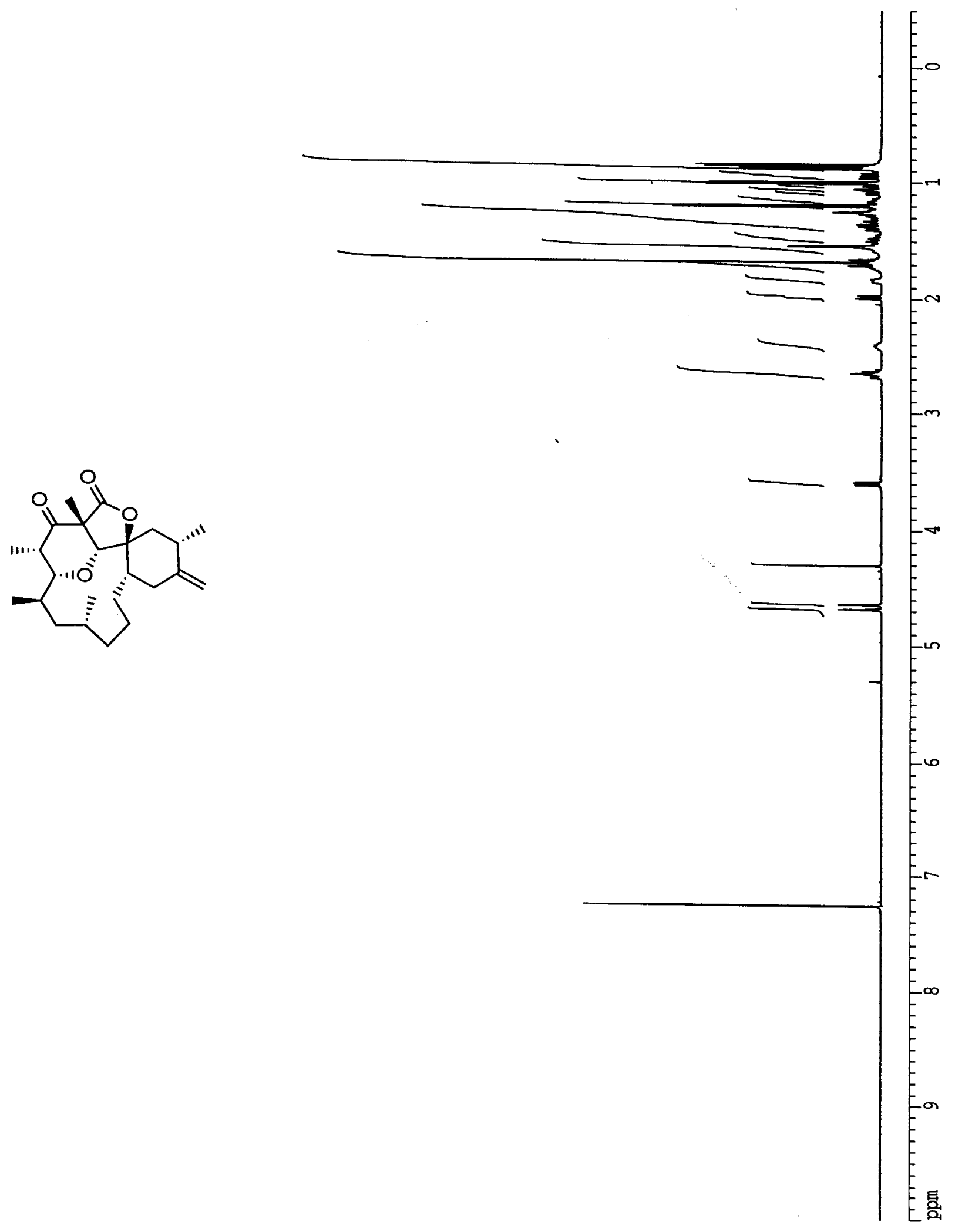

$500 \mathrm{MHz}{ }^{1} \mathrm{H}$ Spectrum of (-)-33 in $\mathrm{CDCl}_{3}$ 

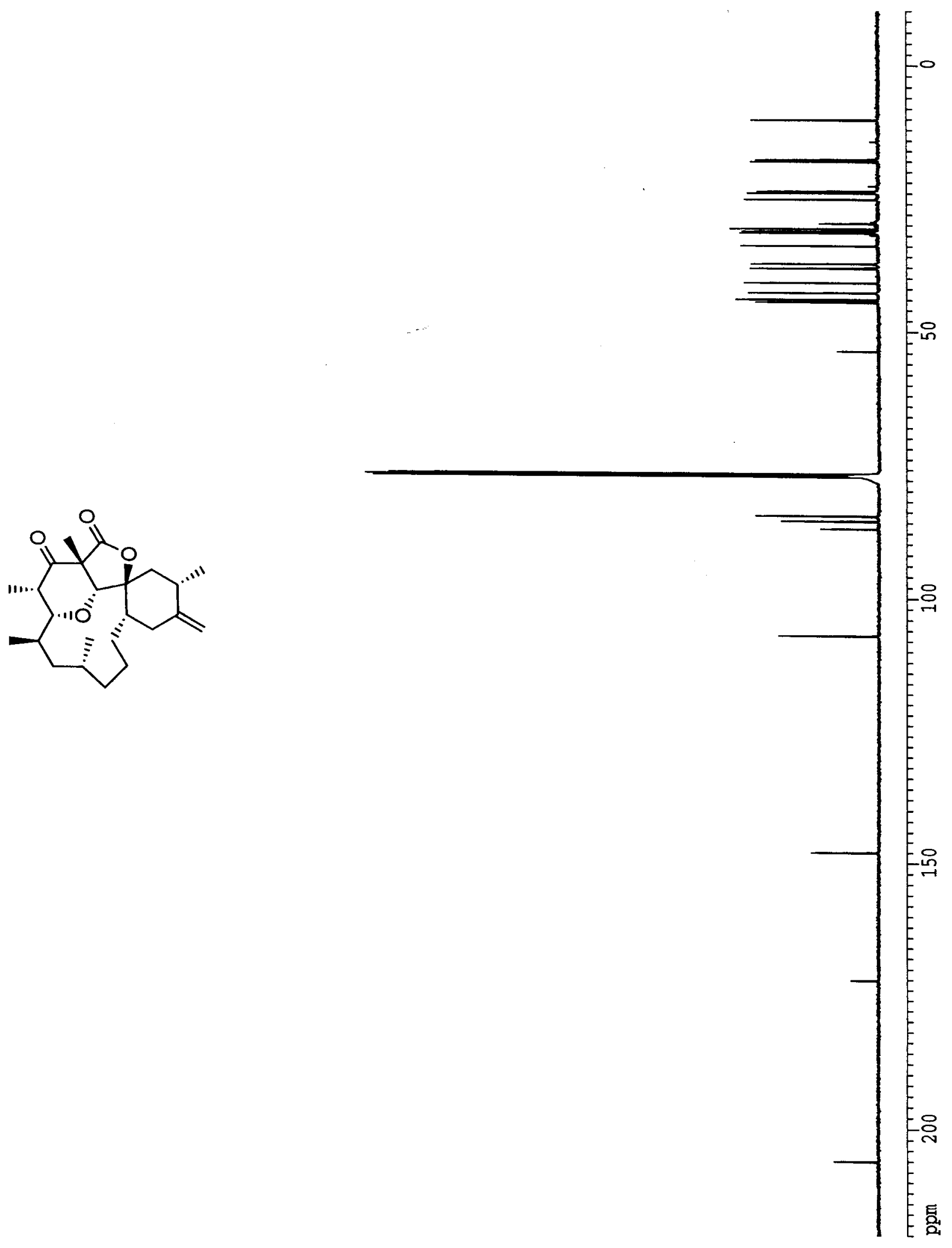

$125 \mathrm{MHz}{ }^{13} \mathrm{C}$ Spectrum of (-)-33 in $\mathrm{CDCl}_{3}$ 

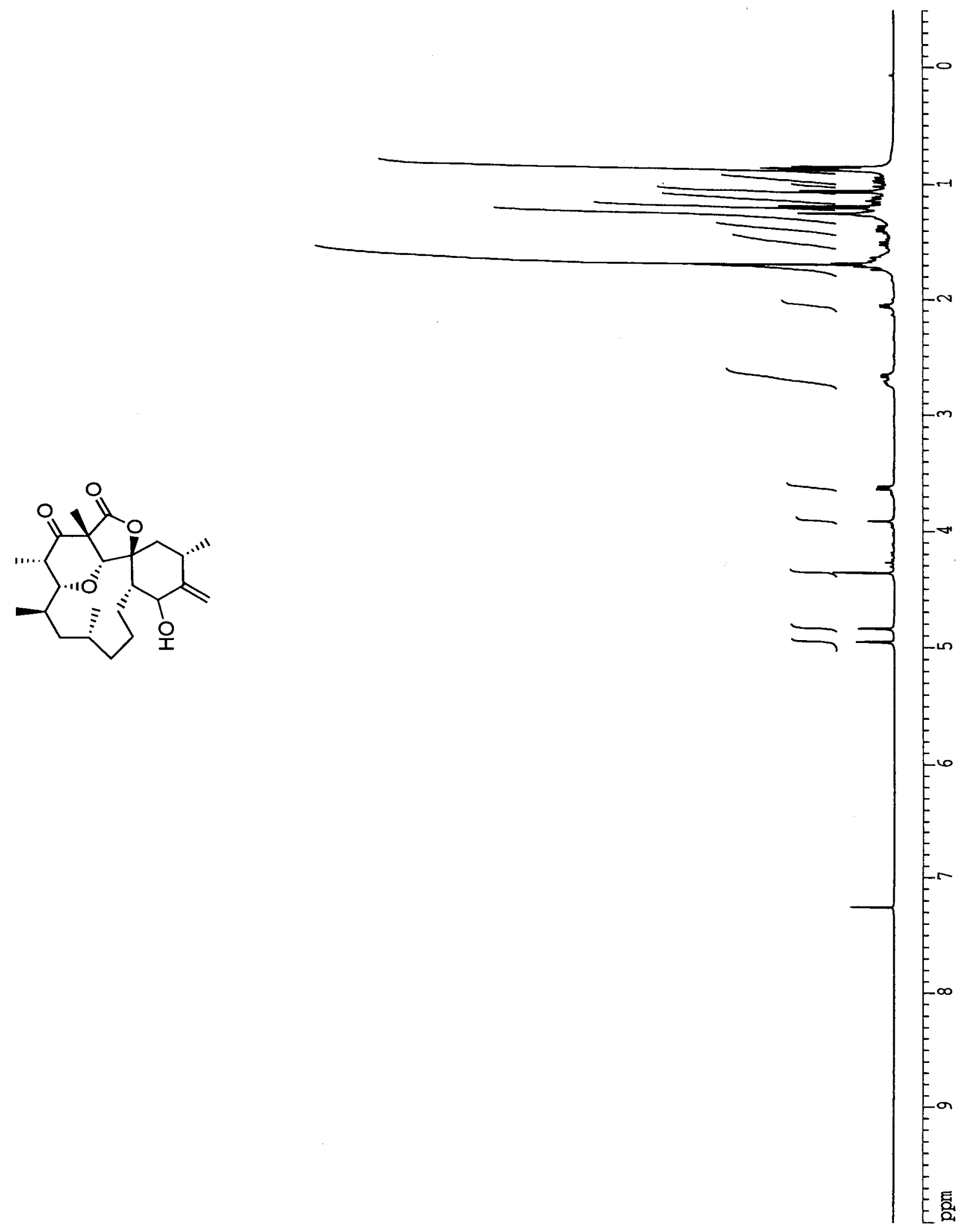

$500 \mathrm{MHz}{ }^{1} \mathrm{H}$ Spectrum of (-)-S4 in $\mathrm{CDCl}_{3}$ 

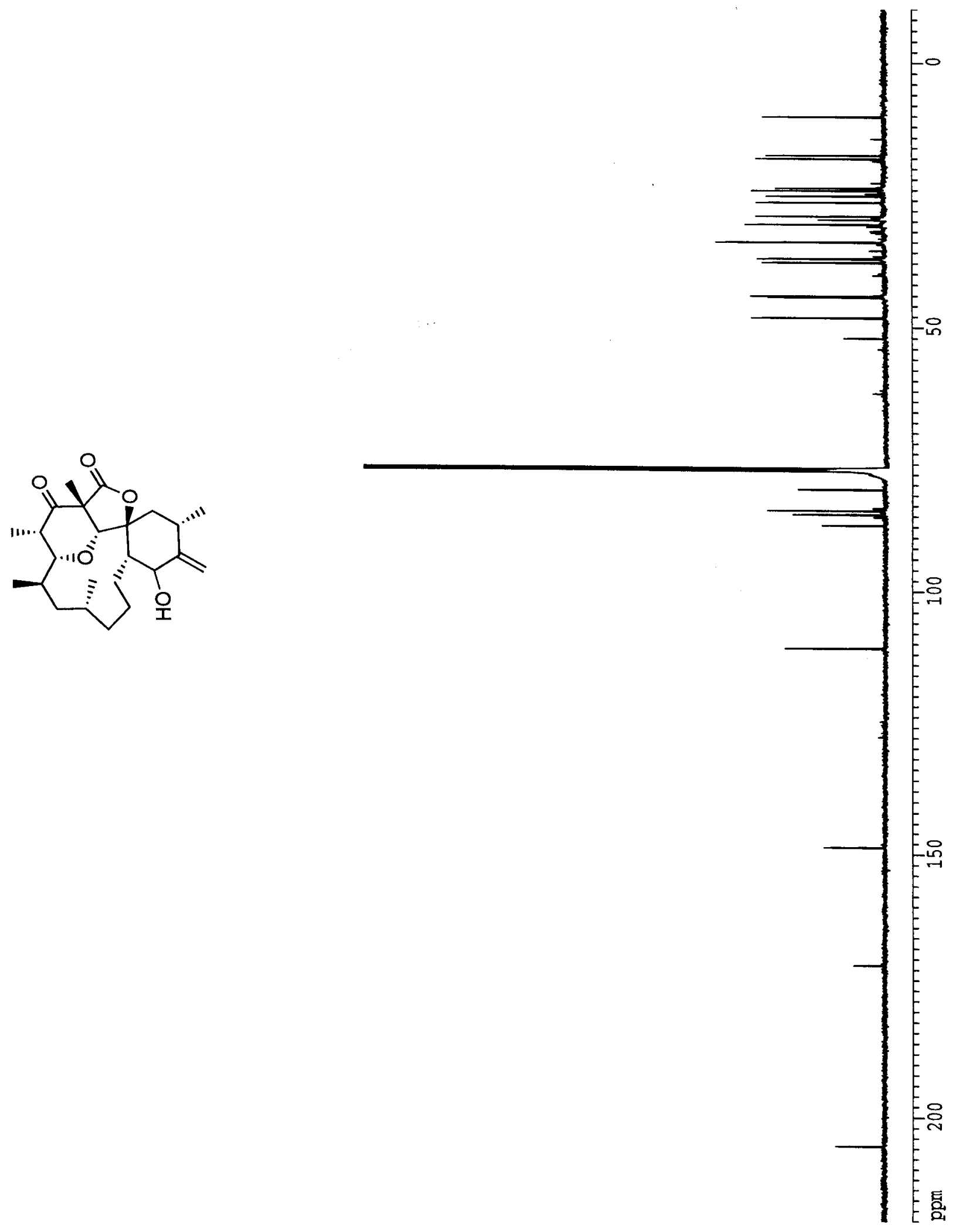

$125 \mathrm{MHz}{ }^{13} \mathrm{C}$ Spectrum of (-)-S4 in $\mathrm{CDCl}_{3}$ 

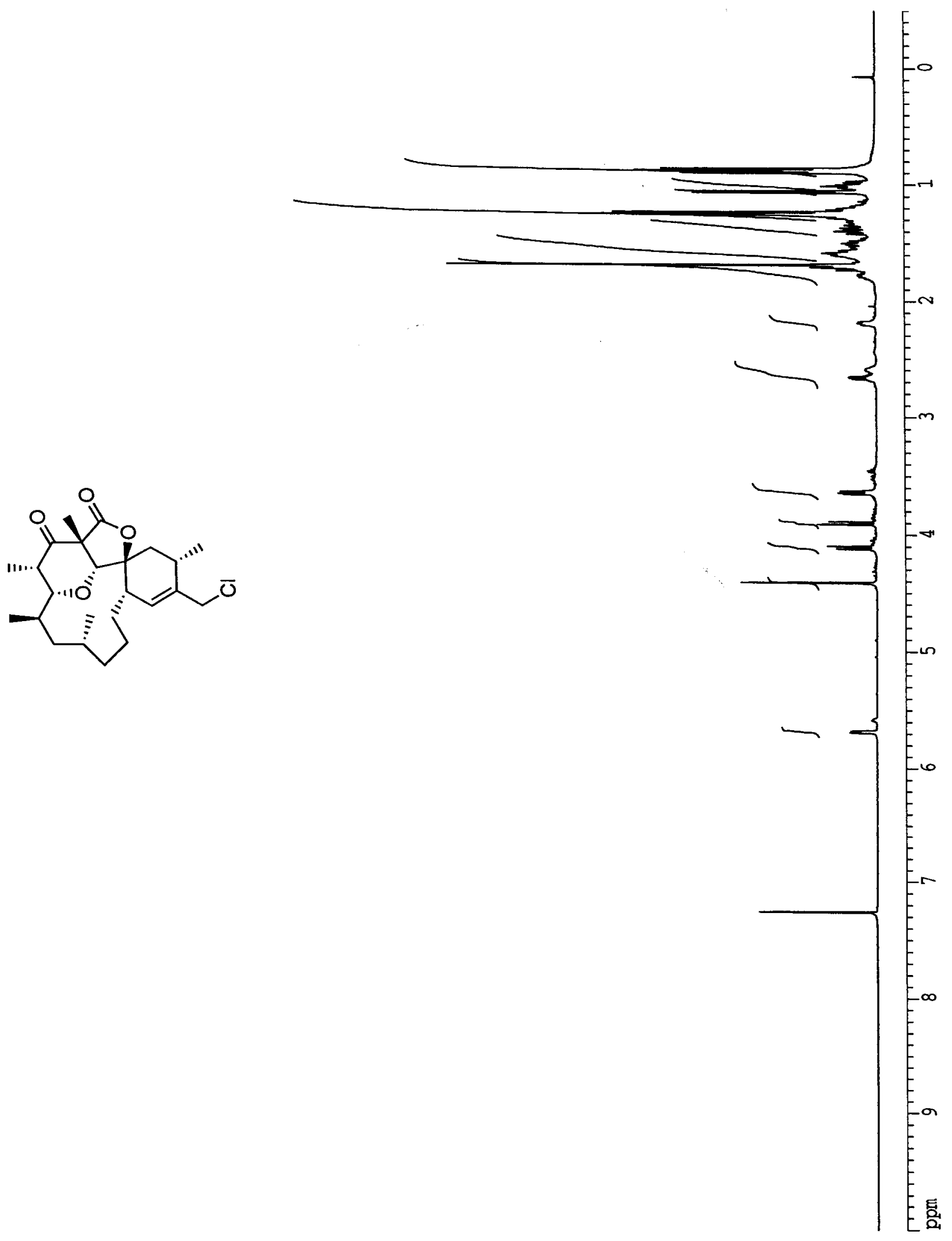

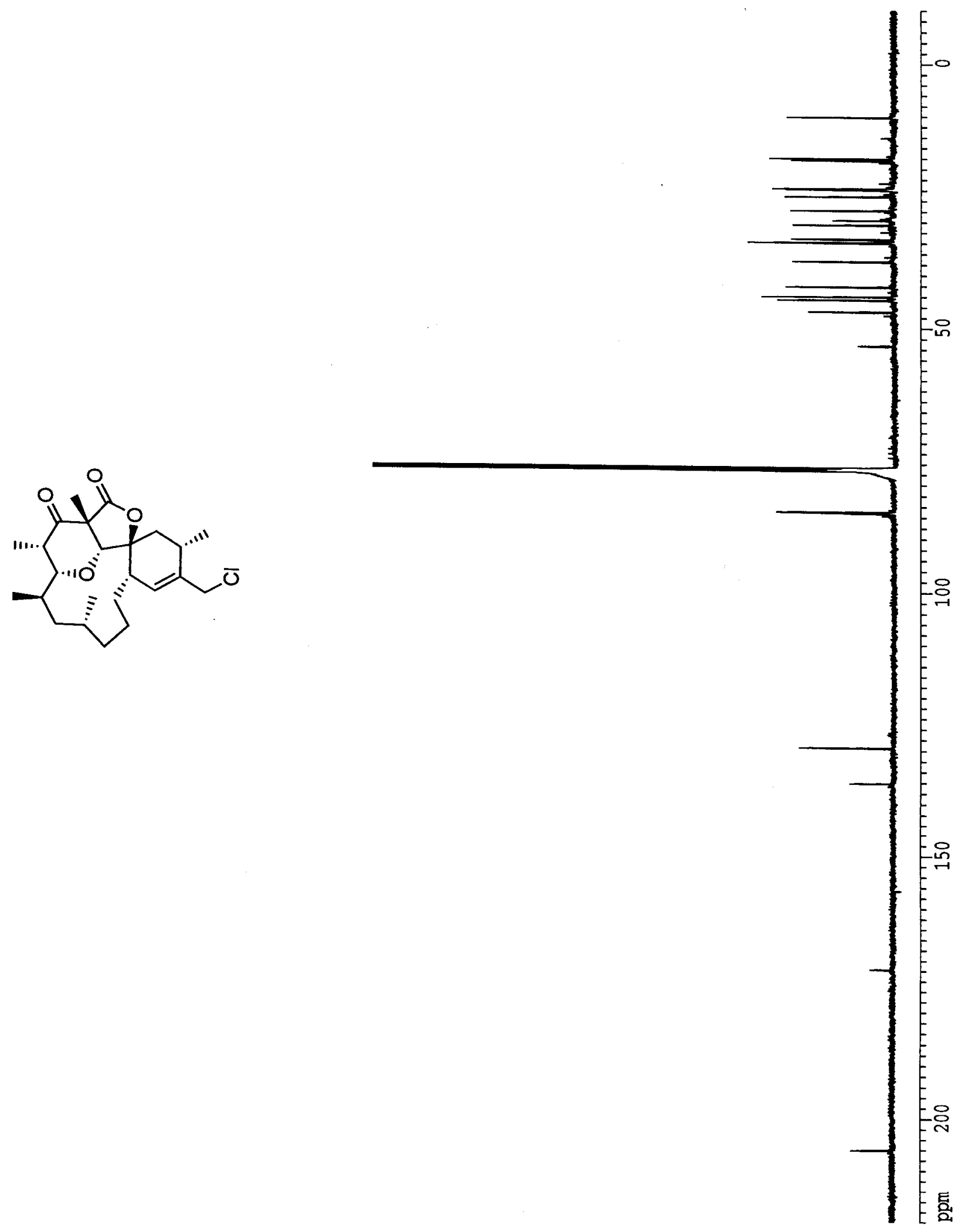

$125 \mathrm{MHz}{ }^{13} \mathrm{C}$ Spectrum of (-)-34 in $\mathrm{CDCl}_{3}$ 

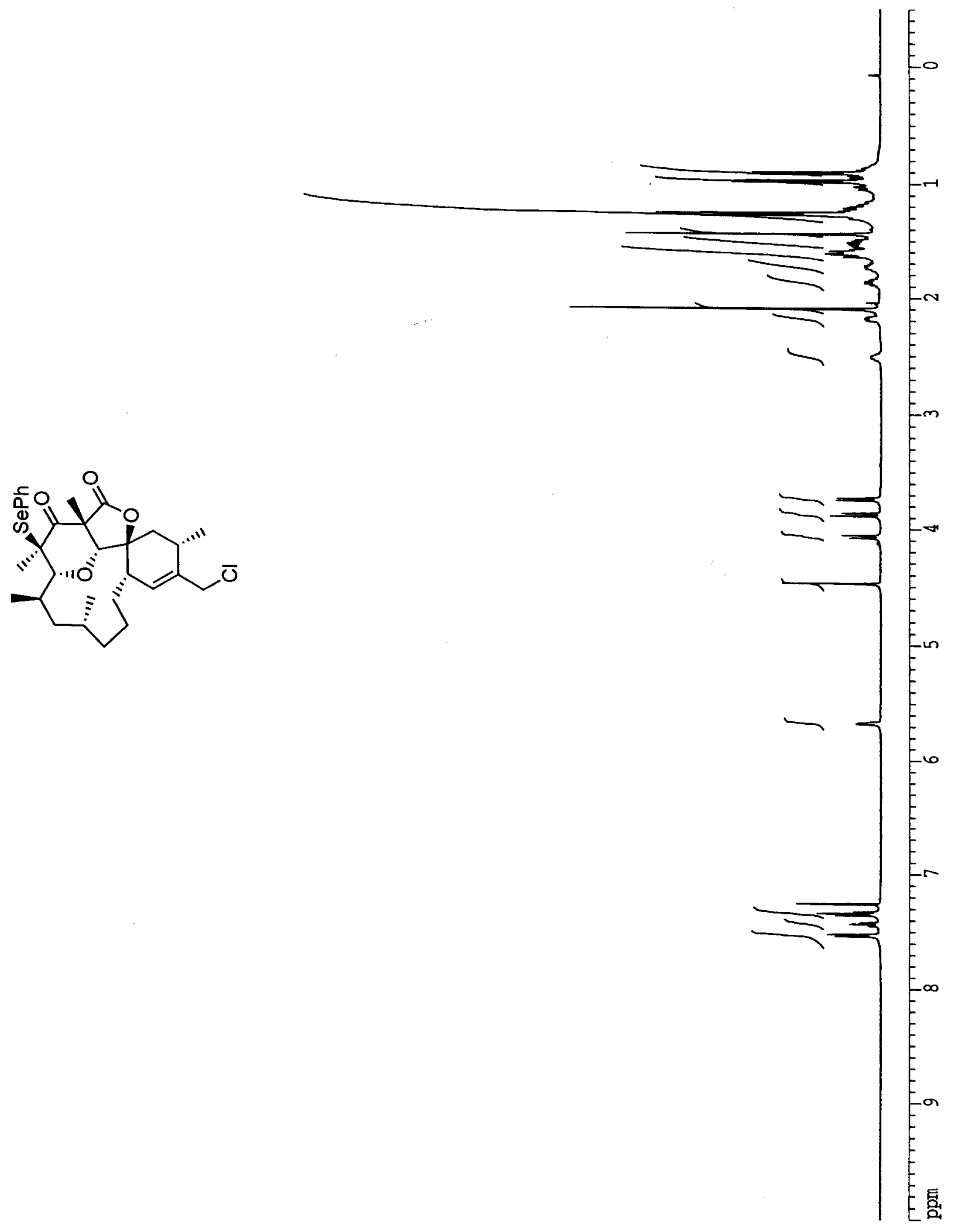

$500 \mathrm{MHz}{ }^{1} \mathrm{H}$ Spectrum of (-)-S5 in $\mathrm{CDCl}_{3}$ 

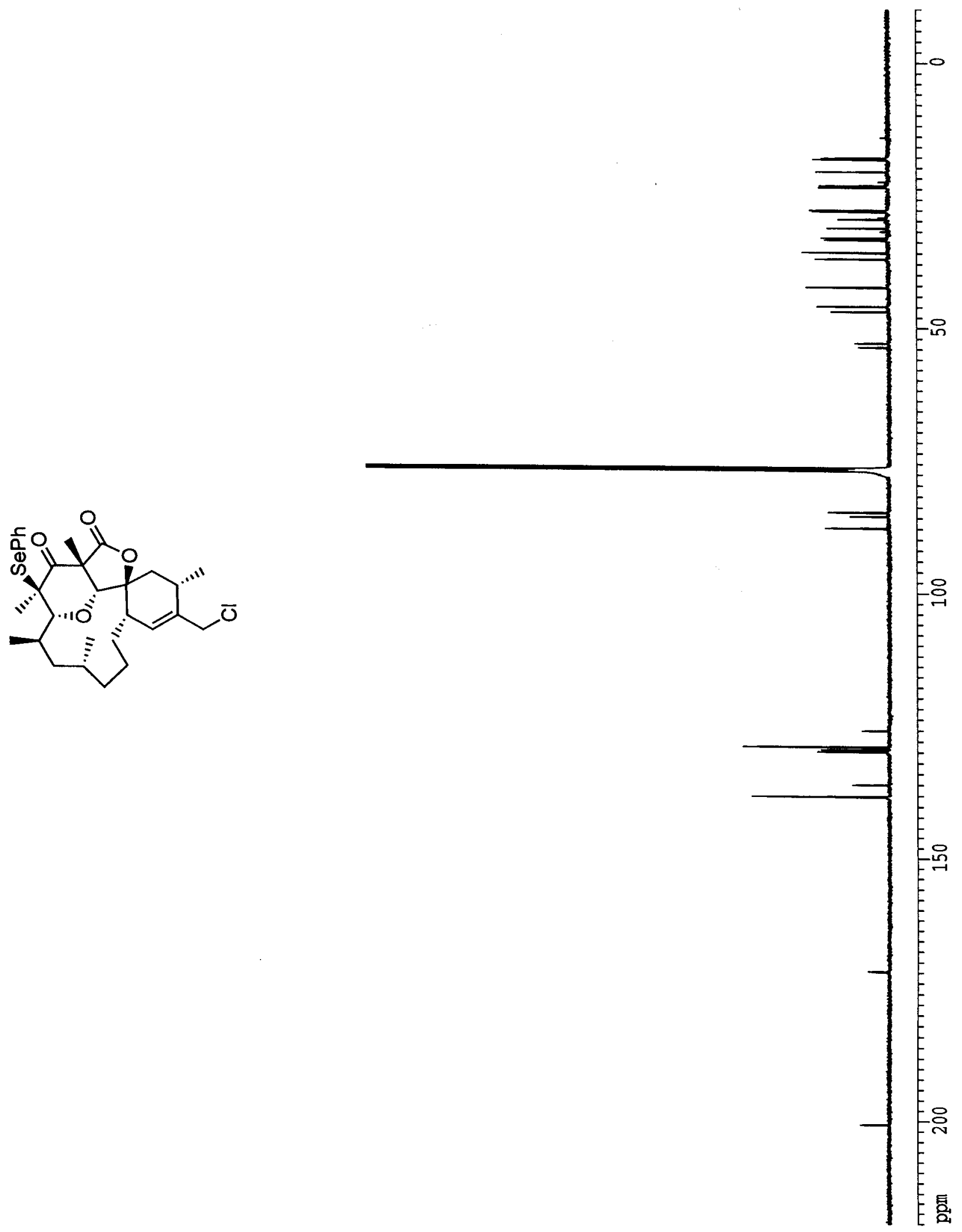

$125 \mathrm{MHz}{ }^{13} \mathrm{C}$ Spectrum of (-)-S5 in $\mathrm{CDCl}_{3}$ 

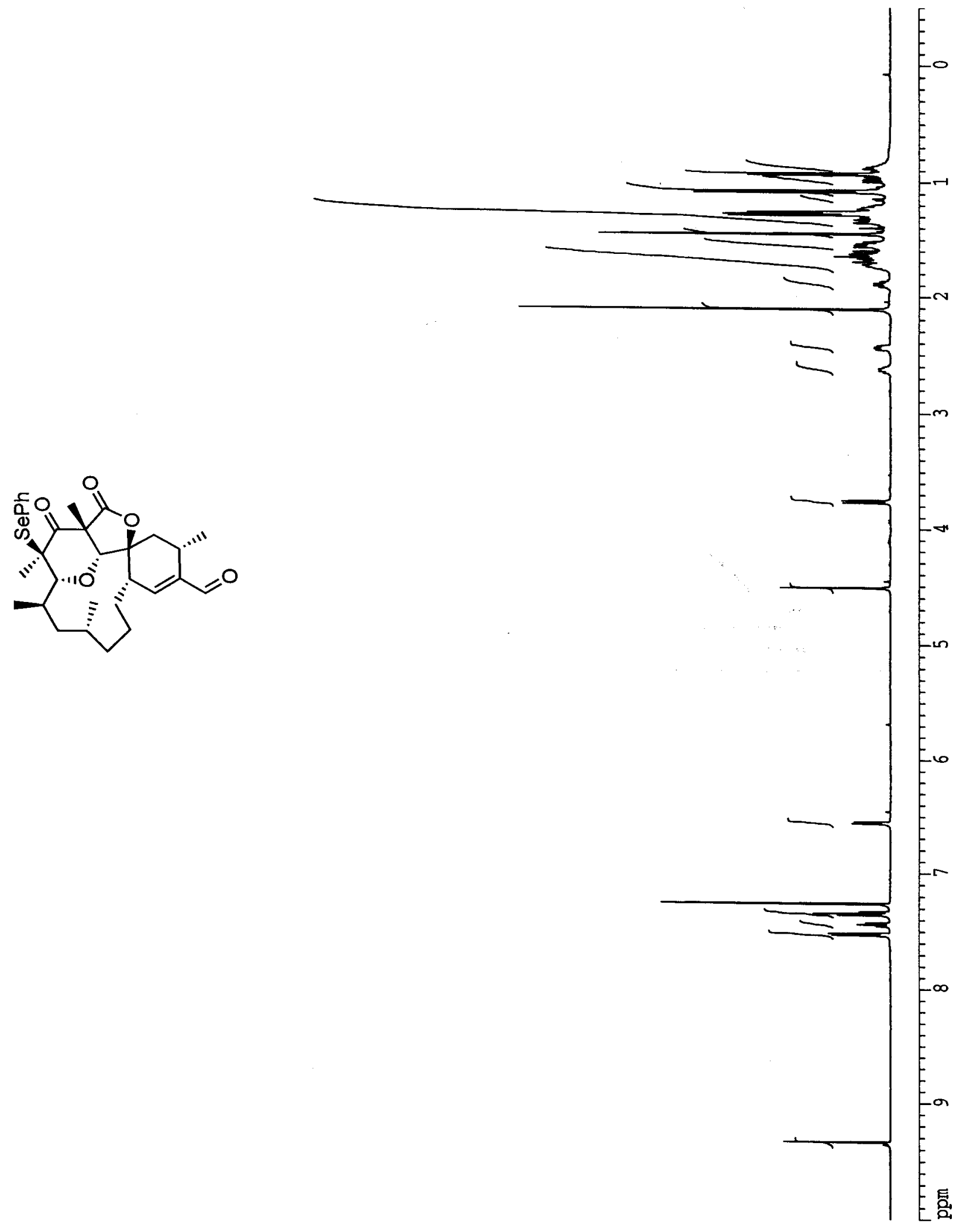

$500 \mathrm{MHz}{ }^{1} \mathrm{H}$ Spectrum of (-)-35 in $\mathrm{CDCl}_{3}$ 

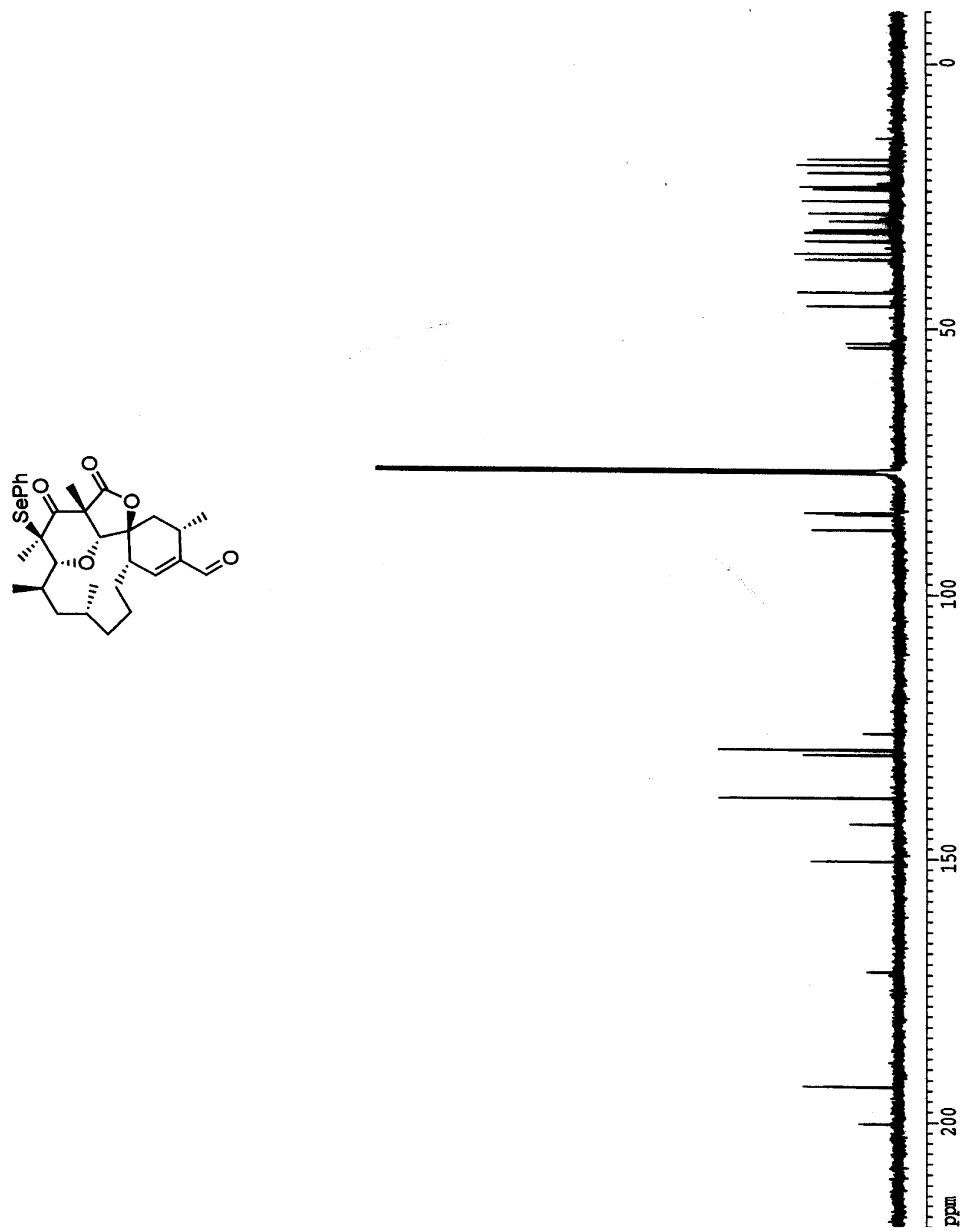

$125 \mathrm{MHz}{ }^{13} \mathrm{C}$ Spectrum of (-)-35 in $\mathrm{CDCl}_{3}$ 

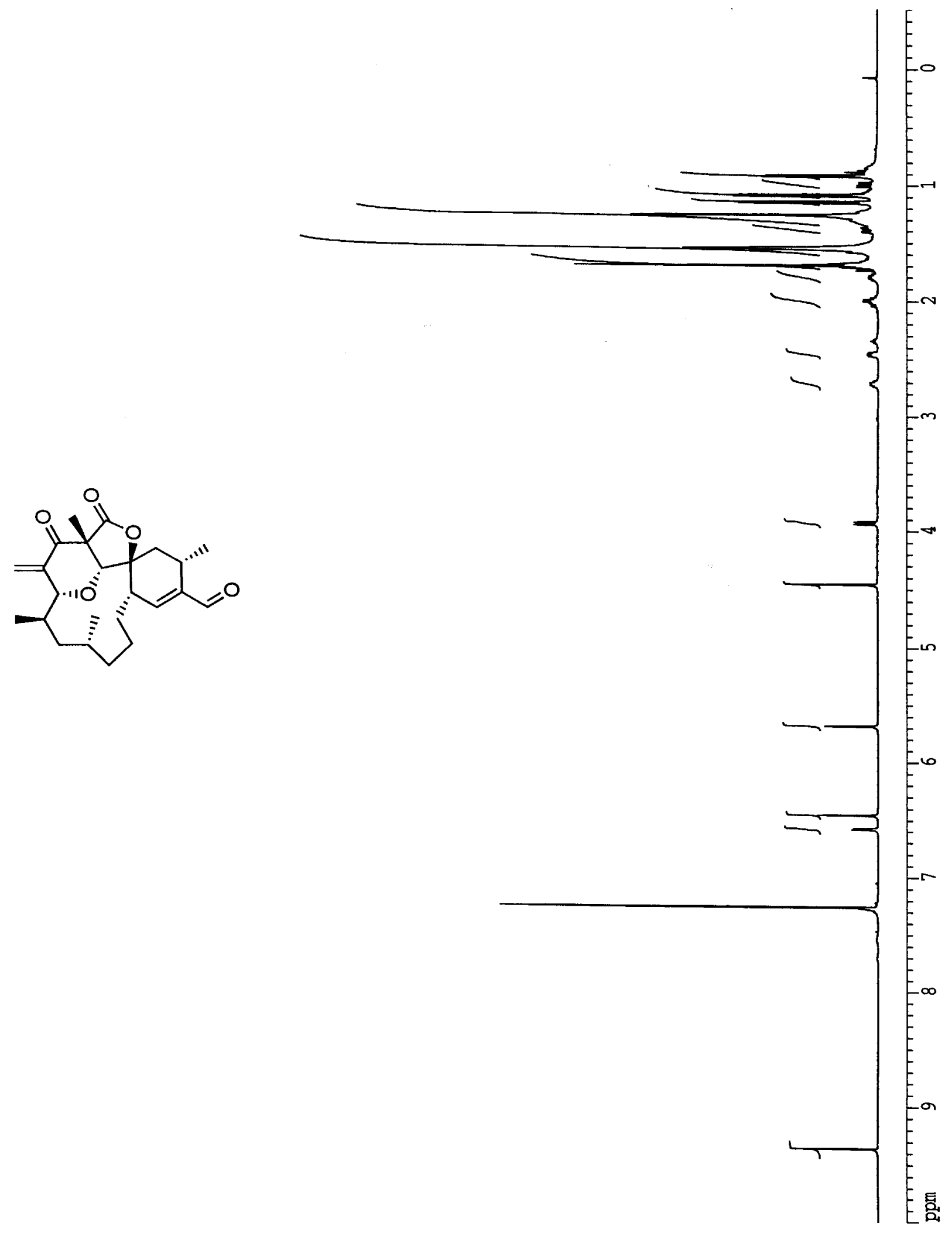

$500 \mathrm{MHz}{ }^{1} \mathrm{H}$ Spectrum of (-)-S6 in $\mathrm{CDCl}_{3}$ 

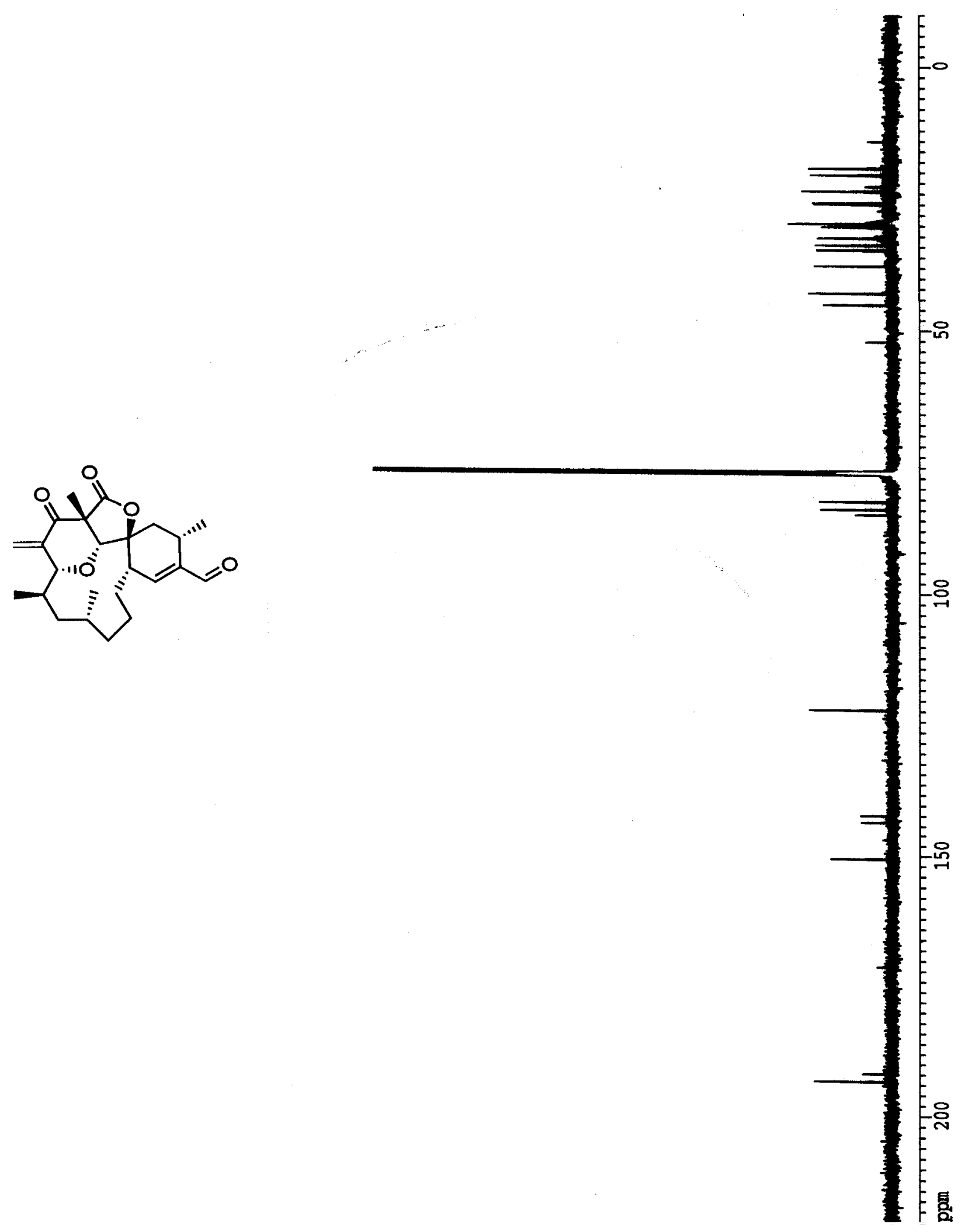

$125 \mathrm{MHz}{ }^{13} \mathrm{C}$ Spectrum of (-)-S6 in $\mathrm{CDCl}_{3}$ 


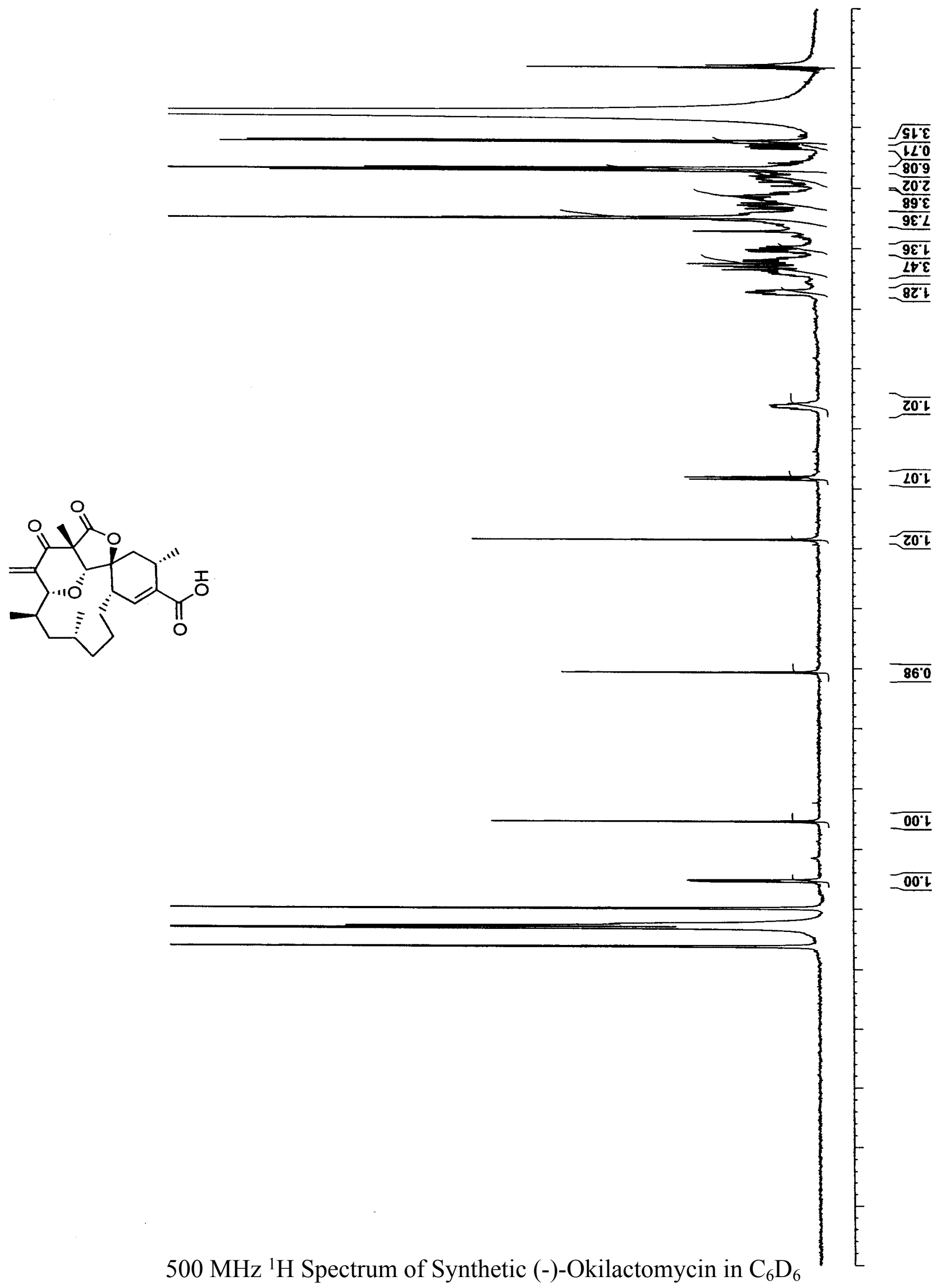




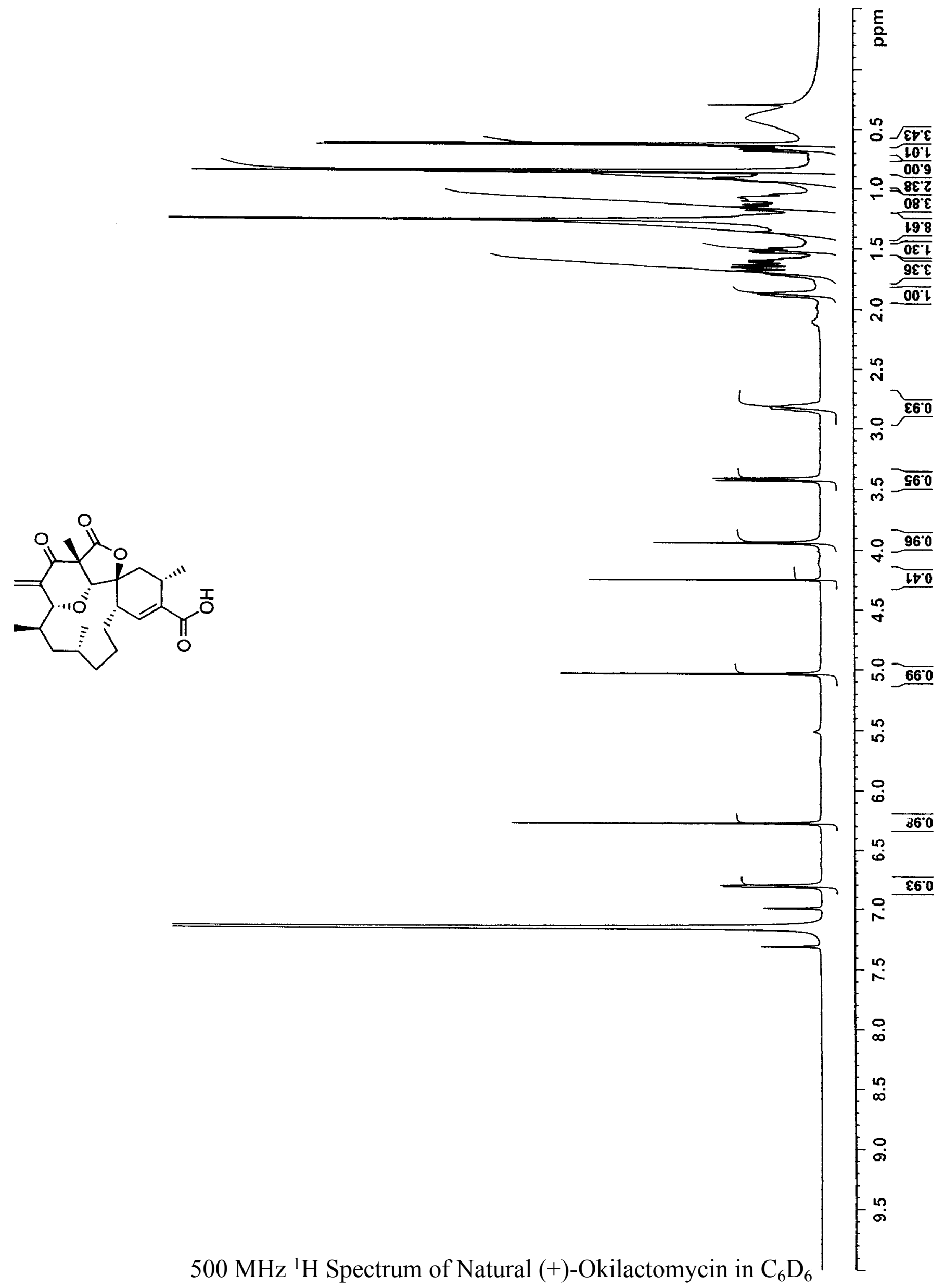




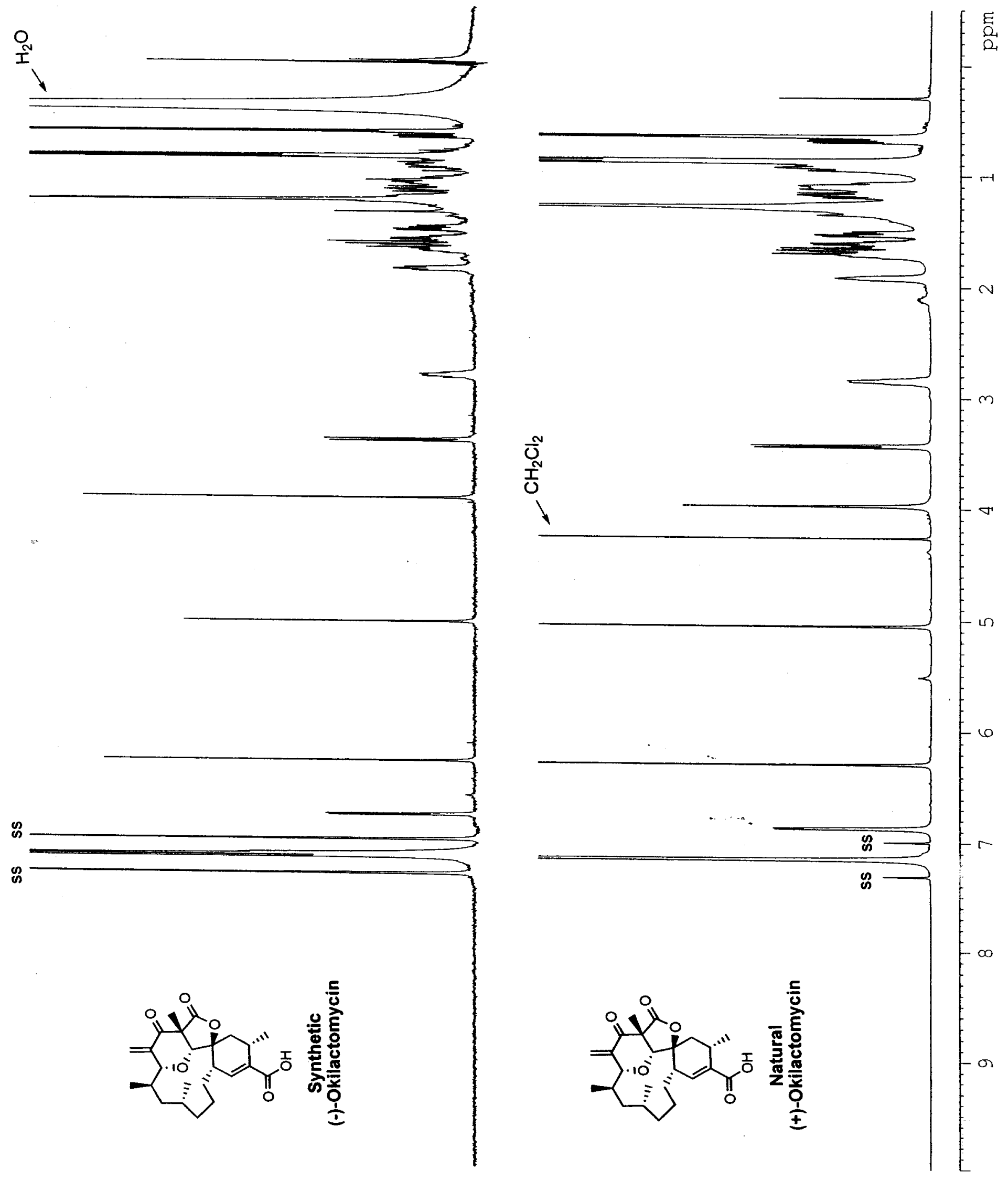

Comparison of ${ }^{1} \mathrm{H}$ Spectra in $\mathrm{C}_{6} \mathrm{D}_{6}$ 